\title{
A DEMOCRATIZAÇÃO DO PODER JUDICIÁRIO E O ACESSO À JUSTIÇA
}

Letícia Braz Mendonça, Ana Augusta Rodrigues Westin Ebaid

Universidade do Oeste Paulista - UNOESTE, curso de Direito, Presidente Prudente, SP. E-mail: lbrazmendonca@gmail.com.

\section{RESUMO}

O presente trabalho tem o objetivo de analisar o Poder Judiciário brasileiro, considerando as questões do acesso à ordem jurídica justa e à efetiva prestação jurisdicional de forma mais democrática. O estudo guia-se em identificar os principais obstáculos enfrentados para democratizar o acesso à justiça e, assim, garantir a solução dos conflitos e realização dos direitos. Constata-se a importância de incrementar garantias, que assegurem os direitos fundamentais e a sua efetividade. $O$ trabalho foi embasado em levantamento bibliográfico, foram efetuadas leituras de legislações, doutrinas e artigos eletrônicos. Os dados foram examinados com a aplicação do método hipotético dedutivo, isto é, as informações coletadas, foram analisadas partindo do geral para o particular.Para garantir o acesso à justiça das classes hipossuficientes, deve-se falar na reforma do judiciário, sendo essencial que haja um desapego da estrutura tradicional, em detrimento da introdução de um sistema judiciário mais flexível, em que os processos sejam mais céleres, menos onerosos, proporcionando, assim, decisões mais rápidas, baratas, e fundamentadas no princípio da equidade e por isto, mais efetivas.

Palavras-chaves: Democracia. Acesso à Justiça. PoderJudiciário.

\section{DEMOCRATIZATION OF THE JUDICIARY AND ACCESS TO JUSTICE}

\begin{abstract}
The present work has the objective of analyzing the Brazilian Judiciary, considering the issues of access to the just legal order and to the effective jurisdictional provision in a more democratic way. The study is aimed at identifying the main obstacles faced in democratizing access to justice and, thus, guaranteeing the resolution of conflicts and realization of rights. The importance of increasing guarantees, which ensure fundamental rights and their effectiveness. The work was based on a bibliographical survey, readings of legislatures, doctrines and electronic articles were carried out. The data were examined with an application of the hypothetical deductive method, that is, as information collected, were analyzed starting from the general to the particular. In order to guarantee access to justice for the under-privileged classes, it is necessary to talk about the reform of the judiciary. It is essential that there be a detachment from the traditional structure, to the detriment of the introduction of a more flexible judicial system, in which the processes are faster, less costly, thus providing quicker, cheaper, and equity-based decisions that are more effective.
\end{abstract}

Keywords: Democracy. Access to justice. Judicial Power.

\section{INTRODUÇÃO}

O Poder Judiciário pós-Constituição Federal de 1988 deve ser compreendido no contexto de Estado "Democrático de Direito". O artigo 10 da Constituição Federal fixa esta definição, onde necessariamente se identificam, como valores, a democracia e o caráter de juridicidade. 
O Estado Democrático de Direito foi instituído para assegurar o exercício dos direitos sociais e individuais, bem como promover a igualdade e a justiça. $\mathrm{O}$ art. 3ㅇ, I, da Constituição Federal estabeleceu ser objetivo do Estado a construção de uma sociedade justa.

Ao Judiciário incube, formalmente, o exercício da justiça, isto é, da função jurisdicional, pautado por linhas capazes de assegurarem a boa qualidade dos resultados.

Por meio do Direito de Ação que obtemos do Estado a prestação de sua atividade jurisdicional, em um caso concreto. Vale ressaltar que o direito de ação e o efetivo acesso à justiça representam a maior das garantias trazidas pela ordem constitucional.

O Estudo jurídico da atualidade se volta para questões formais e dogmáticas, em detrimento dos problemas reais que vem enfrentando o sistema Judiciário. Conduz o presente estudo ao enfoque no acesso efetivo à justiça e aos inúmeros fatores que acarretam a prestação jurisdicional deficiente, tais como: a dificuldade do ingresso em juízo, no que diz respeito aos aspectos econômicos, jurídicos, sociais e culturais, às custas judiciais elevadas, morosidade na prestação jurisdicional, estruturas funcionais e fórmulas procedimentais excessivamente formais.

No panorama atual, constata-se que o Poder Judiciário não está exercendo seu papel como uma instituição acessível, eficiente e ágil, para responder aos reclamos da sociedade. É essencial que o sistema Judiciário não fique alheio aos anseios da sociedade, bem como aos problemas por elas enfrentados. Ou seja, não escape da realidade social para se ocupar apenas com o mundo formal das legislações e tecnicismos processuais. Ele foi instituído para promover a justiça em favor daqueles que lutam por seus direitos. Este trabalho pretende, portanto, levar à reflexão acerca dos problemas existentes, a fim de que se possa encontrar os caminhos para uma ordem jurídica justa e democrática.

\section{METODOLOGIA}

$\mathrm{O}$ artigo respaldou-se em pesquisas bibliográficas, foram realizadas leituras e análise de leis, resoluções, doutrinas e artigos eletrônicos. O presente estudo se vale do métodohipotéticodedutivo, ou seja, os dados colhidos, partiram de uma generalidade, para atingir um fim específico. Foram levados em consideração os fatores históricos, filosóficose axiológicos, para obter resultados críticos e reflexivos sobre a garantiado acesso à justiça e os problemas enfrentados pelo sistema judiciário na atualidade, que acabam refletindo em uma prestação jurisdicional deficiente.

\section{DISCUSSÃO \\ OBSTÁCULOS AO ACESSO À JUSTIÇA}

Como observado, o direito de ter "acesso à justiça" já está previsto em nosso ordenamento jurídico. Por isto, pode-se dizer que o núcleo do problema fundamental dos direitos do homem, hoje, não é tanto o de justificá-los, mas o de efetivá-los. A grande dificuldade enfrentada, no âmbito de uma sociedade democrática, é extrair a máxima eficácia dos direitos fundamentais consagrados no ordenamento jurídico brasileiro, com o objetivo de tornar possível o acesso dos indivíduos ao sistema judiciário. Não se trata de um problema filosófico, mas, sim, de um problema jurídico e político, pois a complexidade se encontra em se saber qual é o modo mais seguro para garantir sua efetivação e impedir que essa garantia continue sendo negligenciada, apesar de já estar prevista juridicamente (MELO FILHO, 2003).

Neste sentido, Cappelleti e Bryant complementam (1988, p. 15):

Embora o acesso efetivo à justiça venha sendo crescentemente aceito como um direito social básico nas modernas sociedades, o conceito de "efetividade" é, por si só, algo vago. A efetividade perfeita, no contexto de 
um dado direito substantivo, poderia ser expressa como a completa "igualdade de armas" - a garantia de que a conclusão final depende apenas dos méritos jurídicos relativos das partes antagônicas, sem relação com diferenças que sejam estranhas ao Direito e que, no entanto, afetam a afirmação e reivindicação dos direitos. Essa perfeita igualdade naturalmente é utópica. As diferenças entre as partes não podem jamais ser completamente erradicadas. A questão é saber até onde avançar na direção no objetivo utópico e a que custo. Em outras palavras, quantos dos obstáculos ao acesso efetivo à justiça podem e devem ser atacados? A identificação desses obstáculos, consequentemente, é a primeira tarefa a ser cumprida.

Ao falar sobre garantia do acesso à justiça, sabe-se que diversos são os obstáculos encontrados, principalmente pelas classes hipossuficientes. A doutrina clássica aponta, como principais empecilhos, os de ordem econômica, social e cultural, que serão tratados, mais detalhadamente, no presente capítulo.

\section{OBSTÁCULO ECONÔMICO}

Dentre os obstáculos citados acima, o econômico é, na maioria das vezes, o mais aparente, pois diz respeito à falta de recursos financeiros que possibilitam o pagamento das despesas judiciais.

De acordo com Reis, Zveibil e Junqueira, "Apesar de a CF/88 prever a inafastabilidade da jurisdição (art 5ㅇ, XXXV), essa regra se torna letra morta, quando se trata de pessoa necessitada. Por isso o filósofo Ovídio sentenciava: 'o tribunal está fechado para os pobres'”. (REIS; ZVEIBIL; JUNQUEIRA, 2013, p. 20)

Conforme esclarece o professor Boaventura de Sousa Santos (1986, p.19):

Quanto aos obstáculos econômicos, verificou-se que, nas sociedades capitalistas em geral, os custos da litigação eram muito elevados e que a relação entre o valor da causa e o custo da sua litigação aumentava à medida que baixava o valor da causa. [...] estudos relevam que a justiça civil é cara para os cidadãos em geral, mas revelam sobretudo que a justiça civil é proporcionalmente mais cara para os cidadãos economicamente mais débeis. É que são eles fundamentalmente os protagonistas e os interessados nas acções de menor valor e é nessas acções que a justiça é proporcionalmente mais cara, o que configura um fenômeno da dupla vitimização das classes populares face a administração da justiça.

$\mathrm{O}$ atual sistema jurídico-processual brasileiro tem, como base, o princípio da igualdade (formal).O artigo 5으, caput, da Constituição Federal estabelece que "todos são iguais perante a lei, sem distinção de qualquer natureza". Porém, na maioria das vezes, não é levado em consideração, que, sem a igualdade material, ocasionará reduzidas possibilidades de uma decisão verdadeiramente justa.

É necessário considerar-se a verdadeira dimensão do princípio da igualdade inserido na Constituição Federal brasileira, que deve ser visto de uma maneira dinâmica, pois é certo que o ordenamento estabelece que todos são iguais perante a lei. Mas a verdade é que, no plano dos fatos, todos são profundamente desiguais. Por isto a igualdade deve ser dinâmica, e não estática, real e não apenas formal. O Estado deve fornecer instrumentos, para suprir às situações de desigualdade, possibilitando, assim, o acesso à igualdade de direito (GRINOVER, 1990). 


\section{OBSTÁCULOS SOCIOCULTURAIS}

Há, também, outros obstáculos que dificultam o acesso ao Judiciário, que estão relacionados a um conjunto de fatores sociais e culturais. Atualmente grande parte da população que aciona o Estado é, justamente, a que possui maior grau de instrução e conhecimento. Em contrapartida, a classe social marginalizada, na maioria das vezes, se sente intimidada diante dos ambientes extremamente formais do Poder Judiciário, além de não ter esclarecimentos suficientes sobre seus próprios direitos individuais e/ ou coletivos e difusos.

A informação e conhecimento sobre seus direitos é um requisito essencial para que seja possível a transformação do conflito em uma ação judicial. Por isto, o desconhecimento de tais garantias pode representar um óbice ao acesso à justiça.

Sobre este tema, o professor Boaventura de Sousa Santos pontua (1986, p. 21):

Em primeiro lugar, os cidadãos de menores recursos tendem a conhecer pior os seus direitos e, portanto, a ter mais dificuldade em reconhecer um problema que os afecta como sendo problema jurídico. Podem ignorar os direitos em jogo ou ignorar as possibilidades de reparação jurídica. Caplowitz (1963), por exemplo, concluiu que quanto mais baixo é o estrato social do consumidor maior é a probabilidade que desconheça os seus direitos no caso de compra de um produto defeituoso. Em segundo lugar, mesmo reconhecendo o problema como jurídico, como violação de um direito, é necessário que a pessoa se disponha a interpor a acção.

Cotidianamente nos deparamos com a ineficácia do Estado em implementar as garantias e os preceitos contidos na Constituição Federal, bem como sua omissão e morosidade na hora de responder aos reclames da sociedade. É necessário que haja uma reforma do Poder Judiciário que viabilize e promova o acesso à justiça, sobretudo à população marginalizada, atenuando, assim, as desigualdades sociais, culturais e econômicas entre os litigantes.

\section{O ACESSO À JUSTIÇA NA CONSTITUIÇÃO DE 1988}

Como já afirmado ao longo do trabalho, o acesso à Justiça é um sinal moderno de cidadania, configurando-se, por si só, como direito fundamental, inerente a todos os seres humanos. Trata-se de mecanismo pelo qual todos os demais direitos são resguardados.

O art. 3ำ I, da Constituição Federal, ao estabelecer ser objetivo do Estado a construção de uma sociedade justa, acaba constatando, justamente, o seu sentido oposto: o de ser o Brasil um país injusto. A injustiça é a razão pela qual a construção de uma sociedade justa seja um objetivo da República, em norma constitucional situada no primeiro Título (dos Princípios Fundamentais). Vê-se, portanto, desde o início da pátria Carta Magna, que o acesso à Justiça se configura em um dos principais objetivos da nação (SILVA, 2012, p. 105).

Ao longo do texto constitucional, há, portanto, diversos instrumentos jurídicos de ordem material e processual, que militam justamente no sentido de se garantir efetivo acesso a meios de consecução da justiça, em seus diversos aspectos.

Sob o ponto de vista material, é possível concluir-se que a Justiça, por si só, é um princípio constitucional. Um verdadeiro direito. Se, como dito, é dever do Estado a promoção da justiça, consequentemente, a justiça é, por si só, um direito de estrutura constitucional. E disto decorrem diversas consequências inerentes a qualquer norma constitucional.

$\mathrm{O}$ acesso à Justiça ganha, entretanto, contornos mais significativos, quando veicula normas processuais. No art. 5ำ XXXV, da Constituição Federal, o constituinte estabeleceu que: "a lei não 
excluirá, da apreciação do Poder Judiciário, lesão ou ameaça a direito". Pode-se verificar duas principais características nesse texto normativo.

A primeira delas reside no dever atribuído ao Poder Judiciário de receber os pleitos jurídicos em que se veiculem lesão a direito ou à obtenção da justiça. Trata-se da consolidação da existência de um órgão próprio e específico (Poder Judiciário), para receber e processar toda e qualquer lesão, efetiva ou potencial, a direitos fundamentais.

A segunda característica decorrente do artigo 50 inciso XXXV, é a configuração do princípio da inafastabilidade da prestação jurisdicional. Pelo próprio conteúdo da norma, toda injustiça (considerando que a justiça é, por si, direito fundamental), efetiva ou potencial, pode ser combatida mediante acesso ao Judiciário, sendo então, inconstitucional qualquer norma que extinga ou, de qualquer modo, diminua a força normativa da inafastabilidade.

\section{AS TRÊS ONDAS DO ACESSO À JUSTIÇA}

Levando em consideração toda essa complexidade gerada pela estrutura social e judiciária, a obra "Acesso à justiça" de Mauro Cappelletti e Bryant Garth apontou três posicionamentos como ondas renovatórias, que emergiram a partir de 1965, representando uma tentativa de atacar os obstáculos à prestação jurisdicional.

A primeira onda traçada nesse movimento de acesso efetivo à justiça, foi à assistência judiciária, que tem o seu fundamento no direito de viabilizar o acesso ao Poder Judiciário, pelas pessoas sem condições financeiras, seja pela falta de contratar um profissional habilitado ou, mesmo, para suportar custas processuais.

Conforme esclarecem Cappellett e Garth (1988, p.47):

Existem limites sérios na tentativa de solução pela assistência judiciária. Antes de mais nada, para que o sistema seja eficiente, é necessário que haja um grande número de advogados, um número que pode até exceder a oferta, especialmente em países em desenvolvimento. Em segundo lugar, mesmo presumindo que haja advogados em números suficiente, no país, é preciso que eles se tornem disponíveis para auxiliar aqueles que não podem pagar por seus serviços. Isso faz necessárias grandes dotações orçamentárias, o que é o problema básico dos esquemas de assistência judiciária.

Cappellett e Garth apontam, como a segunda onda do movimento de acesso à justiça, representação jurídica para os interesses difusos, especialmente na proteção do meio ambiente e do consumidor.

E a terceira onda foi proposta simplesmente como enfoque de acesso à justiça, incluindo os posicionamentos anteriores, além de representar uma tentativa de modificar o modo de ser do processo, visando ao acesso de modo mais articulado e compreensivo.

\section{CONCLUSÃO}

Como já exposto no segundo tópico, o conceito de acesso à justiça não se confunde com acesso ao judiciário. Este pode ser garantido por meio de outros órgãos institucionais, como a Defensoria Pública e o Ministério Público, que são essenciais à função jurisdicional do Estado. Já o tão almejado acesso à justiça, somente ocorre após a concretização do direito material. Pode-se dizer que o julgamento de mérito é uma das formas para de alcançar-se a efetivação do direito. Com isso, conclui-se que a grande responsabilidade de conceder o direito pleiteado cabe ao magistrado, afinal, é o Poder Judiciário que detém a função social de analisar o caso concreto e tornar possível o efetivo alcance do acesso à justiça. 
Não é admissível que, mesmo com tantas garantias dispostas na pátria Constituição Federal brasileira, as minorias ainda continuem excluídas do ordenamento jurídico brasileiro.

A efetivação do acesso à justiça pressupõe, antes de qualquer coisa, a construção de uma cidadania que tenha, como base, o reconhecimento de que toda e qualquer pessoa (sobretudo as que pertencem a grupos minoritários) é detentora do direito de ter acesso à justiça, direito esse que jamais pode ser fraudado pela omissão do Poder Público, já que se trata de direito fundamental, sem o qual se torna impossível a concretização dos demais direitos.

O Poder Judiciário deve superar as estruturas sociais tradicionais e ter consciência de que tem, como função política, a promoção e a efetivação dos direitos garantidos na Constituição Federal, posto que uma decisão judicial amparada na equidade é o instrumento, para que a justiça finalmente seja efetiva e alcance as minorias sociais.

\section{REFERÊNCIAS BIBLIOGRÁFICAS}

BRASIL, Constituição (1988). Constituição da Republica Federativa do Brasil. Brasília: Senado Federal, 1988.

BATISTA RODRIGUES, K. Acesso à Justiça: Instrumentos Viabilizadores. São Paulo: Letras Jurídicas, 2010.

BATISTA DA SILVA, O. A. Democracia Moderna e Processo Civil. In PELLEGRINI GRINOVER A. RAGEL DINAMARCO, C. WATANABE, K. (coord). Participação e Processo. São Paulo: Revistas dos Tribunais, 1988. p. 98-113.

CANELA JUNIOR, O. Controle Judicial de Políticas Públicas. São Paulo: Saraiva, 2011.

CAPELLETTI, M; GARTH, B. Acesso à Justiça. Porto Alegre: Sergio Antônio Fabris Editor, 1988.

CARVALHO, Fabiano; EC45: reafirmação da garantia da razoável duração do processo. In: Reforma do Judiciário: primeiros reflexos sobre a Emenda Constitucional 45/2004. São Paulo: Editora Revista dos Tribunais, 2005.

CINTRA, A.; GRINOVER, A DINAMARCO, C. Teoria Geral Do Processo. 29. Ed. São Paulo: Malheiros, 2013.

DALLARI, D. O Poder dos Juízes. São Paulo: Editora Saraiva, 2002.

MENDONÇA JUNIOR, D. Princípios da Ampla Defesa e da Efetividade no Processo Civil Brasileiro. São Paulo: Malheiros Editores, 2001.

MELO, N. Da Justiça gratuita como Instrumento de Democratização do Acesso ao Judiciário. 2001. Disponível em: <http://www.boletimjuridico.com.br/doutrina/texto.asp?id=1075>. Acesso em: 16 fev. 2017.

MELO FILHO, J. C. de. A democratização do poder judiciário e o acesso á justiça. In: MOTA, C. A. M. S; BUENO R. 50 anos de direitos humanos. São Paulo: Themis, 2003. p.17-35.

MONTESQUIEU, C. Do Espíritos das Leis.São Paulo: Editora Martin Claret, 2004.

MOREIRA DE PAULA, J. L. A jurisdição como elemento da inclusão social: revitalizando as regras do jogo democrático. 1ed. Barueri: Manole Ltda, 2002.

PELLEGRINI GRINOVER, A. Novas tendências do Direito Processual: De acordo com o Constituição de 1988. 2 ed. Rio de Janeiro: Forense Universitária, 1990.

REALE, M. Lições Preliminares de Direto. 27 ed. São Paulo, Saraiva, 2002.

REIS, G. A. S. dos; ZVEIBIL, D. G.; JUNQUEIRA, G. Comentários à lei da defensoria pública. São Paulo: Saraiva, 2013.

SANTOS BEZERRA, P. C. Acesso à Justiça: Um problema ético-social no plano de realização do direito. Rio de Janeiro: Renovar, 2001.

SILVA, J. A. Curso de Direito Constitucional Positivo. São Paulo: Malheiros Editores, 2001.

Comentário contextual à constituição. 8. ed. - São Paulo: Malheiros, 2012. 
SILVIA, FULLIN C. Acesso à Justiça: a construção de um problema em mutação. In: GONÇALVES, S. F.; JOSÉ, R. R.Manual de Sociologia Jurídica.1ed. São Paulo: Saraiva, 2013 p.219-235.

SOUSA SANTOS, B. Introdução à sociologia da administração da justiça. Revista Crítica de Ciências Sociais. n.21. p. 11-37, nov. 1986.

WANDERLEI RODRIGUES, H. Acesso à justiça no Direito Processual Brasileiro. 1 ed. São Paulo: Acadêmica, 1994.

WATANABE, K. Acesso à Justiça e Sociedade Moderna. In PELLEgRINI GRINOVER A. RAGEL DINAMARCO, C. WATANABE, K. (coord). Participação e Processo. São Paulo: Revistas dos Tribunais, 1988. p.128-135. 